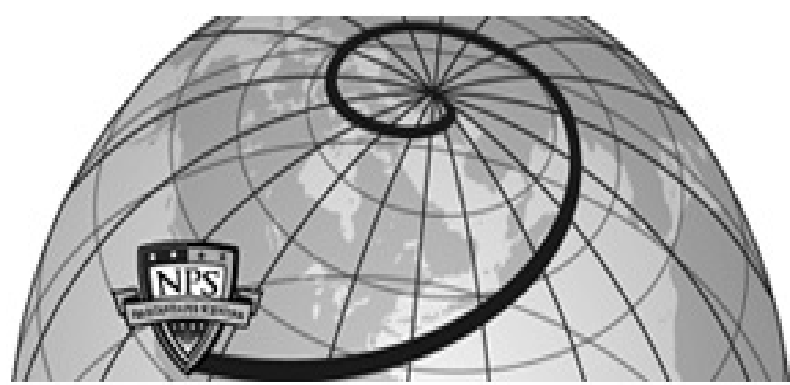

Calhoun: The NPS Institutional Archive DSpace Repository

Dynamic response of an ocean construction barge to various sea states

Donovan, Lawrence K.

Cambridge, Massachusetts; Massachusetts Institute of Technology

https://hdl.handle.net/10945/14963

Downloaded from NPS Archive: Calhoun

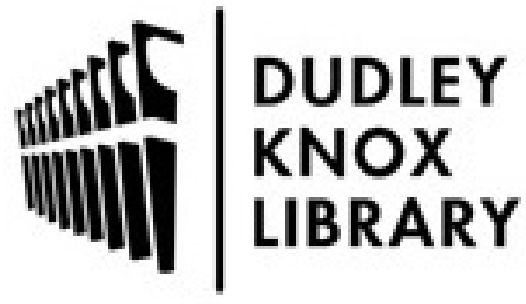

http://www.nps.edu/library
Calhoun is the Naval Postgraduate School's public access digital repository for research materials and institutional publications created by the NPS community. Calhoun is named for Professor of Mathematics Guy K. Calhoun, NPS's first appointed -- and published -- scholarly author.

Dudley Knox Library / Naval Postgraduate School 411 Dyer Road / 1 University Circle Monterey, California USA 93943 


\section{DYNAMIC RESPONSE \\ OF AN OCEAN CONSTRUCTION BARGE \\ TO VARIOUS SEA STATES}

Lawrence K. Donovan 

DYNAMIC RESPONSE OF AN OCEAN

CONSTRUCTION BARGE TO VARIOUS SEA STATES

by

LAWRENCE K. DONOVAN

B. S., University of Notre Dame (1958)

M.S., University of California (1959)

SUBMITTED IN PARTIAL FUL FILLMENT OF THE REQUIREMENTS FOR THE DEGREE OF MASTER OF SCIENCE IN OCEAN ENGINEERING

at the

MASSACHUSETTS INSTITU'TE OF TECHNOLOGY

September, 1970 



\section{DYNAMIC RESPONSE OF AN OCEAN \\ CONSTRUCTION BARGE TO VARIOUS SEA STATES}

\section{by}

\section{Lawrence K. Donovan}

Submitted to the Department of Ocean Engineering in partial fulfillment of the requirements for the degree of Master of Science in Ocean Engineering.

\section{ABSTRACT}

Load handling technology in the sea environment to place heavy and bulky oads accurately on the ocean floor is in its preliminary stages of development. The load handling system is usually mounted on a platform which interacts with he sea surface, imparting dynamic loads to the lifting lines that are not exerienced on land. This study evaluates the response of a specific load handling ystem composed of a crane and constant-tension winch mounted on AMMI pontoon arge to sea states 3,4 , and 5 . The motions of heave, pitch, and roll were oupled by phasing at specific load suspension points and the rms values of the erticle displacement and accelleration at these points were calculated using pectral analysis techniques. It was found that the constant tension winch could ompensate for the motions of sea state 3 but that the probability of exceeding the vinch capability in sea state 4 was large enough to limit operations to missions of ery short duration.

Thesis Supervisor: Martin A. Abkowitz

ritle:

Professor of Naval Architecture 



\section{ACKNOWLEDGEMENTS}

The author wishes to express his sincere appreciation to his thesis supervisor, Professor Martin A. Abkowitz, for his encouragement, understanding and invaluable assistance throughout this project.

Also special thanks are extended to the Ocean Engineering staff of the Naval Civil Engineering Laboratory, Port Hueneme, California for invaluable reference material on previous experiments of this type and to the Ocean Engineering Project Office of the Naval Facilities Engineering Command, Washington, D. C. for suggesting this topic and providing data on the barge. 

Abstract

Acknowledgements

Table of Contents $\quad 4$

List of Figures $\quad 5$

List of Tables

$\begin{array}{ll}\text { List of Symbols } & 7\end{array}$

1 Introduction $\quad 9$

2 Scope of Thesis $\quad$ • 11

3 Method of Analysis $\quad 16$

3.1 Equations of Motion 16

$\begin{array}{ll}3.2 \text { Solution of the Equations } & 17\end{array}$

$\begin{array}{lll}3.3 \text { Hydrodynamic Coefficients } & 18\end{array}$

3.4 Wave Excitation $\quad 22$

3.5 Response Operators 23

3.6 Description of the Seaway 24

$\begin{array}{lll}3.7 & \text { Response Spectra } & 26\end{array}$

4 Discussion of Results

5 Conclusions and Recommendations 38

$\begin{array}{ll}\text { References } & 39\end{array}$

Appendicies
A Evaluation of the Hydrodynamic Coefficients
B Wave Excitation Forces and Moments 



\section{LIST OF FIGURES}

Figure

Page

1 Project AFAR Crane Barge 12

2 Drawing of Project AFAR Crane Barge 13

$\begin{array}{lll}3 & \text { System of Axes } & 21\end{array}$

$4 \quad$ Heave Response Operator for CG 29

$5 \quad$ Pitch Response Operator for CG 29

6 Roll Response Operator for CG $\quad 30$

$7 \quad$ Example of Phase Diagram 30 



\section{LIST OF TABLES}

Table

Page

1 Physical Characteristics of AMMI Crane Barge

$2 \quad$ Hydrodynamic Coefficients

$3 \quad$ Hydrostatic Coefficients

4 Excitation Amplitudes and Phase Angles

27

$5 \quad$ Motion Response Operators

28

6 Response Operators at Points of Interest

7 Pierson-Moskowitz Spectral Data for a Fully Developed Sea

$8 \quad$ Values for: Response ${ }^{1 / N}=\mathrm{f}_{1}(\mathrm{~N})(\mathrm{rms})$

$9 \quad$ Response Spectrum Values

10 Response rms Values 



\section{LIST OF SYMBOLS}

a Wave amplitude

$a_{\text {ij }}$ Matrix element for verticle plane motion

A Area of the underwater section $\left(\mathrm{B}^{*} \times \mathrm{H}\right)$

B* Local section beam

B Barge beam

BG Verticle distance between $\mathrm{CB}$ and $\mathrm{CG}$

$\mathrm{C}_{\mathrm{S}} \quad$ Section coefficient

CB Center of buoyancy

CG Center of gravity

E Total energy or integrated area under spectral curve

F Force

Acceleration due to gravity

Verticle distance between CG and the metacenter

Barge draft

Moment of inertia

Roll moment

Amplitude of roll excitation

Verticle distance from the keel to $\mathrm{CG}$

Effective radius of gyration

Barge length

Boom length

Pitch moment

Amplitude of pitch excitation

Mass of barge

Roll angular velocity

Pitch angular velocity

Time

Period

Linear velocity in the $\mathrm{x}$ direction 

LIST OF SYMBOLS (Cont'd.)

Linear velocity in the $\mathrm{z}$ direction

Displacement volun'.

$\mathrm{X}, \mathrm{Y}, \mathrm{Z}$ Forces acting positively along the $\mathrm{x}, \mathrm{y}$, and $\mathrm{z}$ axes

$\mathrm{x}, \mathrm{y}, \mathrm{z} \quad$ Orthogonal axes system

${ }^{\mathrm{y}} \mathrm{CB} \quad$ Local sectional center of buoyancy distance from the $\mathrm{z}$-axis

Distance of CG from origin of coordinate system along $\mathrm{x}$-axis

Boom verticle angle with positive $\mathrm{x}$-axis

Displacement weight

Phase lag between wave and barge motion $(i=z, \Theta$ or $\phi)$

Boom horizontal angle with positive $\mathrm{x}$-axis

Wave surface elevation

Pitch angle

Wave length

Dummy variable along $\mathrm{x}$-axis

Mass density

Roll angle

Angle between barge heading and incident wave train

Wave angular frequency

Frequency of encounter between barge and wave. 



\section{INTRODUCTION}

Construction involves the lifting and transportation of heavy equipment and all kinds of materials. For dry land application, a whole spectrum of simple and complex load handling systems have been designed and built to achieve the completion of construction projects of all kinds and magnitudes. As man now moves to a completely different environment for construction, the ocean floor and the sea above it, it is found that load handling technology is in its preliminary stages of development at best. To accomplish underwater construction there is a need to lift and lower and also recover heavy and bulky objects in the open seas.

One of the conventional systems often used for this type of load handling consists of a winch and a line with the line being run out on some kind of boom. The winch and boom are mounted on a small floating platform and a load is suspended at the end of the line. As the platform interacts with the waves of the ocean surface, the platform motions cause the load to oscillate and this in turn generates oscillation in the line tension. In order to design a load handling system for a specific job, the ocean engineer must be able to predict how the dynamic tension in a line from a given platf $m$ will vary with the sea state and specific loads attached to the end of the liris.

Because of the U.S. Navy's interest in lifting and lowering loads to 6,000 foot depths, a development program has been carried out at the Naval Civil Engineering Laboratory (NCEL) to predict the dynamic stress response of lifting lines in Oceanic operations. These studies ${ }^{1,2,3}$ and others have resulted in a method of predicting lifting line stresses for various ideally shaped loads using the sea induced motions of the platform at the last point of contact with the line as one of the major inputs.

Much work has been accomplished in hydrodynamics for the prediction of ship motions in both regular and irregular seaways since the introduction of the strip theory of ship motions by Korvin-Kroukovsky in 1955.4 Rightfully this research into the optimization of the hydrodynamic characteristics of transportation type ship structures belongs in the field of Hydrodynamics or Naval Architecture. 

The Ocean Engineer on the other hand is most likely concerned with a working platform that is barge shaped and may be moored or remains fairly stationary in the seaway.

Thus, this thesis will concern itself with the prediction of the motions of a fairly simple ocean engineering construction load handling system in a seaway. The goal of this work is to provide a simplified method of analysis that will give a good first estimate of platform vertical accellerations at points on the platform where lifting lines would receive the greatest effect from the barge motions. The data developed by this study should be accurate enough to allow sizing of lifting lines within engineering safety and prediction of the operational limitation of the system as a function of sea state. 



\section{SCOPE OF THE THESIS}

In 1970, the Navy executed project $\mathrm{AFAR}^{5}$ which involved the implantment of an acoustical array on a sea mount in 1300 feet of water. It was determined that the most economical load handling system to support the project was to construct work barges from 90 feet $\times 28$ feet $\times 5$ feet AMMI pontoon sections or from basic 5 feet $\times 5$ feet $\times 7$ feet pontoon cans. In the operations plan ${ }^{5}$, the construction was administratively limited to sea state 3 on the Beaufort scale, however no analysis was provided to indicate what magnitude of barge motions or line tensions that could be expected at that or higher sea states.

This thesis will specifically analyze the interaction of the Crane Barge of Project AFAR shown in Figures 1 and 2 with various sea states starting with sea state three. The barge is composed of one AMMI pontoon section fitted with a Harbor Master, $180 \mathrm{HP}$, propulsion unit in each corner, a 30 ton capacity standard construction crane, and a Leithiser constant-tension winch. The propulsion system can be controlled so that the barge can remain on a specific station, without mooring, within the accuracy required for the implantment. The physical characteristics of the barge are listed in Table 1.

The method of analysis to be used will employ the linearized equations of motion for pitch, heave and roll for a regular unidirectional train of waves approaching the barge from the starboard quarter. The wave frequency dependent coefficients and the wave excitation amplitudes and phase lags of the equations will be determined by comparing a method of calculation for the coefficients published by Muga ${ }^{6}$ of NCEL to the experimentally determined coefficients of Vugts ${ }^{7}$ for a rectangular cylinder with a beam-draft ratio of 8 , and using the coefficients felt to be most accurate. The equations will then be solved for input waves of seven different wave lengths. A response operator for each of these wave lengths for the verticle acceleration will be determined with phase coupling of pitch, heave and roll at four points of interest: the deck amidships at both the bow and stern and the end of the crane boom with the boom at both the port beam position and 60 degrees after the port bow. A smooth curve for the response operator 



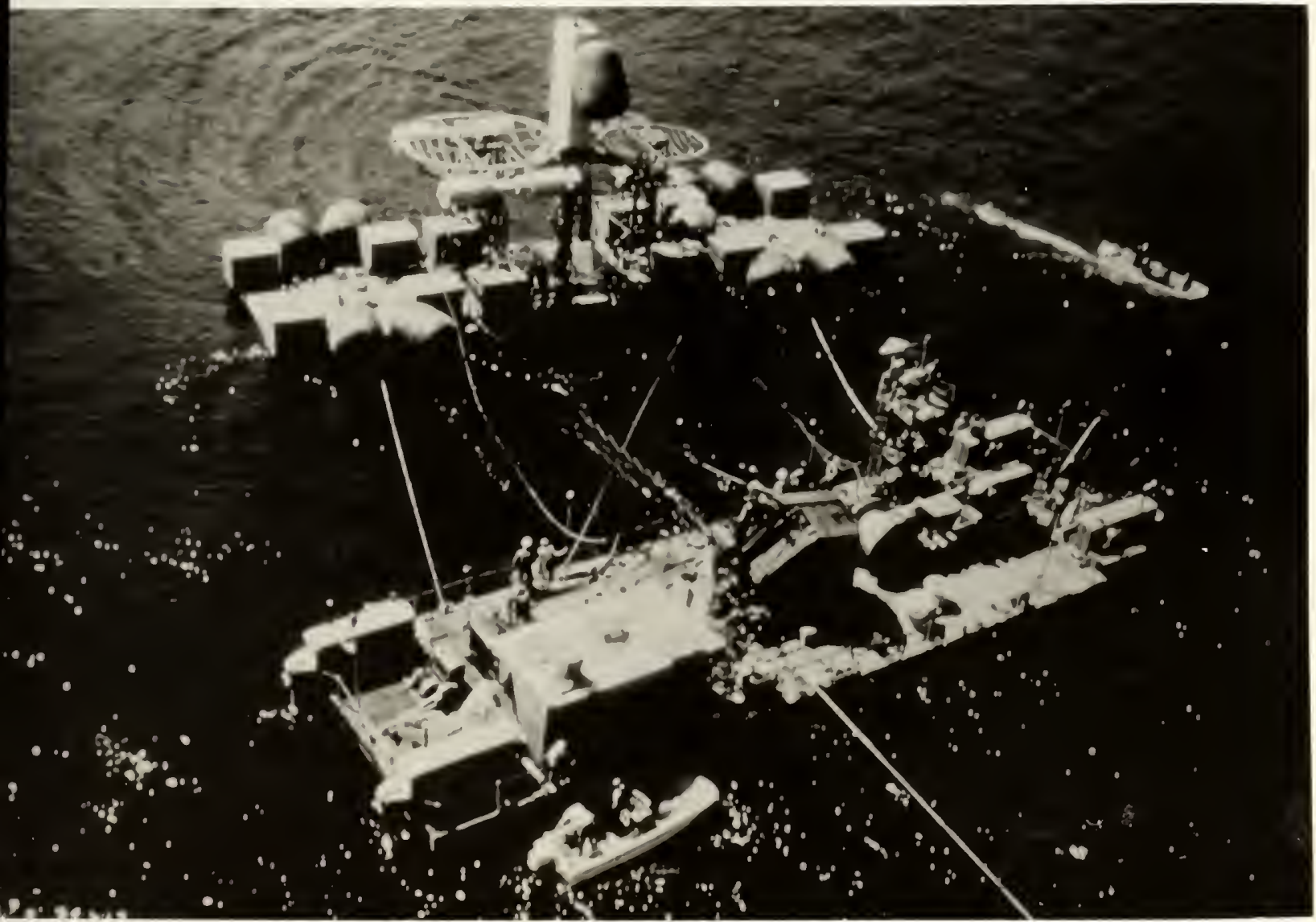

Figure 1. Project AFAR Crane Barge 



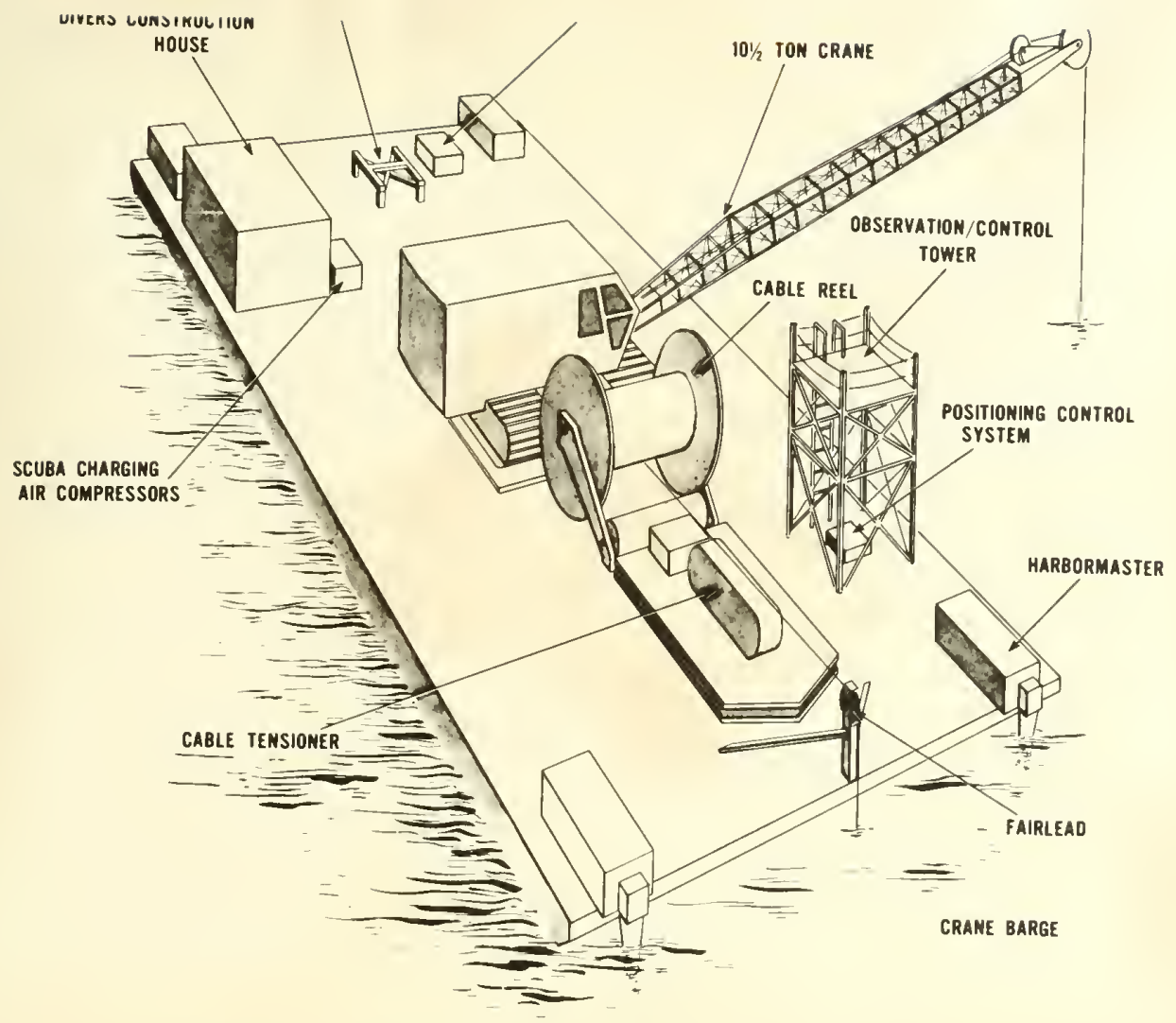

Figure 2. Drawing of Project AFAR Crane Barge 

TABLE 1

PHYSICAL CHARACTERISTICS OF AMMI CRANE BARGE

\begin{tabular}{|c|c|}
\hline Length & 90 feet \\
\hline Beam & 28 feet \\
\hline Calm water draft & 3.5 feet \\
\hline Displacement & 252 L. Tons \\
\hline Weight & $564,480 \mathrm{lbs}$ \\
\hline $\mathrm{G} \overline{\mathrm{M}}$ & 147.25 feet \\
\hline I & $7.33 \times 10^{6}$ Slug-ft ${ }^{2}$ \\
\hline $\mathrm{f}$ & $7.125 \times 10^{5}$ Slug-ft \\
\hline Mass & 17,640 Slugs \\
\hline
\end{tabular}



at each of the points will be drawn and using spectral analysis techniques, a response spectrum for several sea states will be determined. From the response spectrum, the R.M.S. value of the accelerations for each sea state will be calculated and statistical information developed which can provide the basis for limiting operations above certain sea states. 



\section{METHOD OF ANALYSIS}

\subsection{Equations of Motion}

The linearized equations of motion for the barge will be developed along the technique suggested by Abkowitz ${ }^{8}$. The motions are separated into motions in the horizontal plane and motions in the verticle plane. Because of the difficulty and complexity in determining cross coupling coefficients and the uncertainty in the state of the art in handling all six degrees of freedom, only pitch and heave will be considered in the verticle plane and only roll in the horizontal plane. The excitation due to waves is the only dynamical response term that will be considered on the right hand side of the equations. It is assumed that the barge can maintain position with no forward speed and thus control and propulsion forces are neglected. The regular wave train is assumed to be unidirectional and approaches the barge from the starboard quarter or $45^{\circ}$ off the bow. To simplify the analysis, the regular wave is broken down into two equal components of wave length $\sqrt{2} \lambda$, one from directly head-on and the other from beam-on. Pitch and heave will be affected by head-on waves while roll and heave will be affected by beam-on waves. The center of gravity is assumed to be at the water line, amidships.

The notation to be used is that $\mathrm{D}=\frac{\mathrm{d}}{\mathrm{dt}}$ and a symbol with a dot over it, $\dot{\Theta}$, is the first derivative with respect to time. A symbol with two dots over it, $\ddot{z}$ is the second derivative with respect to time. The derivatives for the hydrodynamic coefficients, $\left(\frac{\partial \mathrm{Z}}{\partial \dot{\mathrm{w}}}\right)_{0}$ will be written as $\mathrm{Z}_{\mathrm{W}}$ which is the partial derivative with respect to the vertical accelleration taken at the original conditions with the barge at rest. In this notation it should be remembered that $\mathrm{p}=\dot{\phi}$ and $\mathrm{q}=\dot{\Theta}$.

Thus the general linearized equations of motion for the barge system are:

$\underline{\text { Heave }}$

$$
\begin{array}{ccc}
{\left[\left(z_{\dot{w}}-m\right) D^{2}+z_{w} D+z_{z}\right] z+\left[\left(z_{\dot{q}}+m x_{G}\right) D^{2}+z_{q} D+z_{\Theta}\right] \Theta} & \left.=-z_{1} e^{i(\omega t-\epsilon} z\right) \\
{\left[a_{11}\right]} & z+\left[a_{12}\right] & \Theta=A_{1}(t)
\end{array}
$$




$$
\begin{aligned}
& \text { r. pid } \\
& \text { (1) } 10
\end{aligned}
$$


$\underline{\text { Pitch }}$

$$
\begin{aligned}
& {\left[\left(M_{\dot{w}}+m x_{G}\right) D^{2}+M_{w} D+M_{z}\right] z+\left[\left(M_{\dot{q}}-I_{y}\right) D^{2}+M_{q} D+M_{\Theta}\right] \Theta=-M_{1} e^{i\left(\omega t-\epsilon_{M}\right)}} \\
& {\left[a_{21}\right] \quad z+\quad\left[a_{22}\right] \quad \Theta=A_{2}(t)}
\end{aligned}
$$

$\underline{\text { Roll }}$

$$
\left[\left(K_{\dot{p}}-I_{x}\right) D^{2}+K_{p} D+K_{\phi}\right] \not D=-K_{1} e^{i\left(\omega t-\epsilon_{K}\right)}
$$

where $\mathrm{Z}_{1}, \mathrm{M}_{1}$ and $\mathrm{K}_{1}$ are the amplitudes of the excitation and $\epsilon$ is the phase lag. Since there is no forward speed, $w$ was used in place of $w_{e}$, the frequency of encounter. Thus $w_{\mathrm{e}}=w=\sqrt{\frac{2 \pi g}{\lambda}}$, the wave frequency. The coefficients on the left hand side of the equations are independent of time but may be a function of $w$. Due to the choice of the CG and the constant section of the barge, the coupling coefficients will be zero.

\subsection{Solution of the Equations}

Solution of the equations of motion is accomplished by solving for the roots of the determinant of the coefficient matrix for equations (1) and (2) or by just solving for the roots as in equation (3). The solution will be of the form:

$$
f_{j}(t)=\sum_{k=1}^{m} C_{k} e^{\sigma_{k} t}+\left(f_{j o}\right)^{i\left(\omega t-\epsilon_{j}\right)}
$$

where $f_{j}(t)$ is the chosen independent variable, $m$ is the number of indepcndent variables in the system, $\mathrm{C}_{\mathrm{k}}$ arc the constants of integration, $\sigma_{\mathrm{k}}$ are the roots of the determinant, $\left(f_{j}\right)_{0}$ is the amplitude of the steady state response and $\epsilon_{j}$ is the phase lag. 

The solution of equations (1) and (2) in determinant form is:

$$
z(t)=\frac{\left|\begin{array}{ll}
A_{1}(t) & a_{12} \\
A_{2}(t) & a_{22}
\end{array}\right|}{\left|\begin{array}{ll}
a_{11} & a_{12} \\
a_{21} & a_{22}
\end{array}\right|} \quad(5) \quad \text { and } \Theta(t)=\frac{\left|\begin{array}{ll}
a_{11} & A_{1}(t) \\
a_{21} & A_{2}(t)
\end{array}\right|}{\left|\begin{array}{cc}
a_{11} & a_{12} \\
a_{21} & a_{22}
\end{array}\right|}
$$

The steady state solution of equation (3) is:

$$
\phi(t)=-\frac{K_{1} e^{i\left(\omega t-\epsilon_{K}-\Gamma\right)}}{\sqrt{\left[K_{\phi}-\left(K_{p}-I_{x}\right) \omega\right]^{2}+\left(K_{p} \omega\right)^{2}}}
$$

where

$$
\Gamma=\tan ^{1} \frac{K_{p} \omega}{K_{\phi}-\left(K_{p}-I_{x}\right) \omega^{2}}
$$

3.3 Evaluation of the Coeffieients

The hydrodynamie eoeffieients are independent of time beeause they are made up of various derivatives defined by referenee only to the initial equilibrium condition. They may depend on the vehiele size, shape and inertial distribution and on the frequeney of exeitation sinee the motion of the vehiele on the free surfaee generates waves. The frequeney of this response must be the same as that of the exeitation in order for the eoeffieients to remain time independent. A system of axes is defined for this analysis as shown in figure 3 with the forees $X, Y$, and $\mathrm{Z}$ positive in the direetion shown, piteh positive in the bow up direetion and roll positive with the starbord side down. The origin is taken at the eenter of gravity of the barge whieh is assumed to be direetly above the keel amidships at the ealm water line. Thus $x_{G}=y_{G}=z_{G}=0$. Eaeh of the eoeffieients will 

generally include derivatives which are either inertial, damping, or hydrostatic in nature. In the case of damping, only damping due to wave generation will be considered.

There has been significant research carried out in recent years to develop methods of theoretical calculation for the more important hydrodynamic coefficients. References 7 through 12 are representative of the current state of the art and provide an excellent reference list. Coefficients for motion in the verticle plane are better defined and understood than those in the horizontal plane. Some of the coupling coefficients have never been measured due to the difficulty in devising an accurate experiment.

Methods for calculating the coefficients were developed for the Navy by Kaplan and Putz (1962) ${ }^{13}$ for the CUSS I Project MOHOLE Barge in a moored condition and by Muga (1966) ${ }^{6}$ for the missile recovery barge FISHOOK, also in a moored condition. Although the barges considered in these studies were slightly more complex, the method of coefficient calculation is applicable. Frank (1967) ${ }^{14}$ has published section: coefficient values for the center section of a series-60 ship, however, with a smaller beam-draft ratio than the barge of this study. Vugts (1968) ${ }^{7}$ has also published the sectional coefficients of long rectangular cylinders for various beam-draft ratios, some closely approximating the conditions of this study.

To simplify this analysis, the method of calculations published by Muga ${ }^{6}$ and the experimental data of Vugts ${ }^{7}$ will be used as best fitting a rectangular box shaped barge. The sectional derivatives calculated by Muga's equations will be compared with the experimental data of Vugts and the experimental derivative will be used whenever available. Because of the symmetry of the barge, it is assumed that the sectional coefficients are constant over the length of the barge. Details of the derivation of each coefficient is presented in Appendix A. Table 2 lists the nondimensional values of the frequency dependent coefficients calculated by Muga's equations compared to those determined by Vugts. 



\section{TABLE 2}

\section{HYDRODYNAMIC COEFFICIENTS}

(Calculated vs Experimental Data)

(Note: $\rho=$ sectional mass density)
$\lambda$
$\underline{50}$
$\underline{100}$
$\underline{150}$
$\underline{200}$
$\underline{300}$
$\underline{500}$
$\underline{600}$

Heave Added Mass $=\frac{\mathrm{Z}_{\dot{\mathrm{w}}}}{\rho \mathrm{A}}$
Muga 6
2.51
2.76
3.77
4.27
5.01
5.27
5.41
Vugts $^{7}$
2.75
2.75
3.08
3.70
3.90
4.50
5. 00
Heave Damping $=\frac{\mathrm{Z}_{\mathrm{w}}}{\rho \mathrm{A}} \quad \sqrt{\frac{\mathrm{B}}{2 \mathrm{~g}}}$

$\begin{array}{llllllll}\text { Muga } & 0.51 & 2.30 & 3.24 & 3.61 & 3.52 & 3.09 & 2.85 \\ \text { Vugts } & 1.45 & 2.13 & 2.25 & 2.22 & 2.20 & 2.10 & 1.95\end{array}$

Pitch Added Moment $=\frac{\mathrm{M}_{\dot{q}}}{\rho \mathrm{AL}^{2}}$

$\begin{array}{llllllll}\text { Muga } & 0.209 & 0.230 & 0.312 & 0.356 & 0.418 & 0.439 & 0.451 \\ \text { Vugts } & 0.229 & 0.229 & 0.256 & 0.308 & 0.325 & 0.375 & 0.417\end{array}$

Pitch Damping $=\frac{M_{q}}{\rho A L^{2}} \sqrt{\frac{B}{2 g}}$

Muga
0.043
0.191

0.270

0.301

0.293

0.257

0.237

Vugts

0.121

0.177

0.187

0.183

0.175

0.162

Roll Added Mass $=\frac{\mathrm{K}_{\dot{\mathrm{p}}}}{\rho \mathrm{AB}^{2}}$

Muga (insufficient information to make the calculations)
Vugts
0.098
0.122
0.139
0.146
0.148
0.146
0.145

Roll Damping $=\frac{\mathrm{K} p}{\rho \mathrm{AB}^{2}} \sqrt{\frac{\mathrm{B}}{2 \mathrm{~g}}}$ (Note: Muga Values all $\times 10^{-2}$ )
Muga
0.0153
0.0104
0.0081
0.0065
0.0050
0.0029
0.0023
Vugts
0.0300
0.0375
0.0270
0.0180
0.0080
0.0050
0.0030 

Figure 3. System of Axes

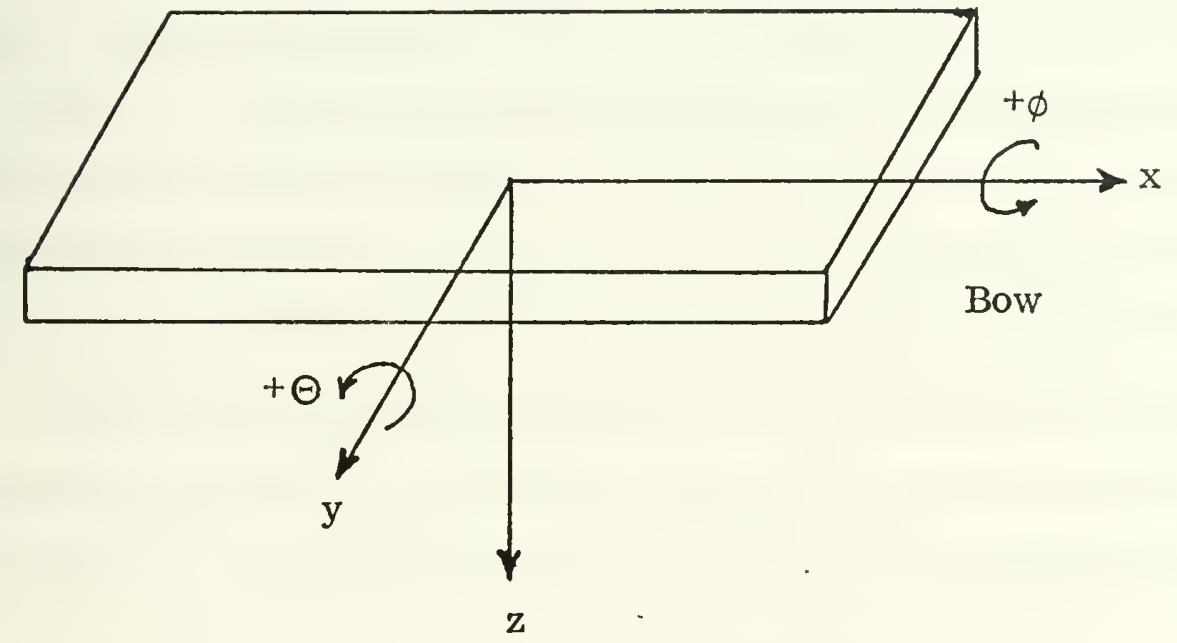

TABLE 3

HYDROSTATIC COEFFICIENTS

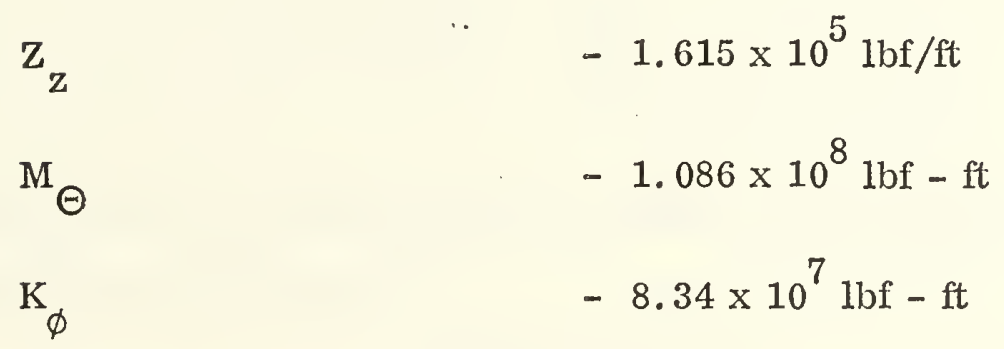





\subsection{Wave Excitation}

The wave induced effects on the barge are composed of inertial, damping and displacement components of the wave induced force acting on individual ship sections of length. For this study it has been assumed that a unidirectional train of regular waves approaches the barge at a 45 degree angle with the bow at some wave length, $\lambda$. The incoming wave length has been broken down into a head-on component and a beam-on component, each of wave length, $\sqrt{ } 2 \lambda$. The wave excitation forces and moments on the right hand side of equations (1), (2) and (3) will be defined in terms of the hydrodynamic coefficients previously derived in Section 3.3.

The details of the definition of the wave excitation forces and moments are explained in Appendix B. It should be noted that the general form of the equations for the forces, $\mathrm{F}_{\omega}$ or moments, $\mathrm{M}_{\omega}$, in Appendix $\mathrm{B}$ are of the general form:

$$
\mathrm{F}_{\omega} \text { or } \mathrm{M}_{\omega}=\mathrm{A}_{\omega} \cos \omega t+\mathrm{C}_{\omega} \sin \omega t
$$

which can also be written as

$$
F_{\omega} \text { or } M_{\omega}=\sqrt{A_{\omega}{ }^{2}+C_{\omega}{ }^{2}} \cos (\omega t-\epsilon)
$$

where

$$
\epsilon=\tan ^{-1} \quad \frac{\mathrm{C}_{\omega}}{\mathrm{A}_{\omega}}
$$

If it is understood that only the real part of complex notation will be considered, then equation (10) can be written as

$$
F_{\omega} \text { or } M_{\omega}=\sqrt{A_{\omega}^{2}+C_{\omega}^{2}} e^{i(\omega t-\epsilon)}
$$



Comparing this expression to the right hand side terms of the equation of motion, it can be seen that for heave as an example.

$$
-\mathrm{Z}_{1}=\sqrt{\mathrm{A}_{\omega}^{2}+\mathrm{C}_{\omega}^{2}}
$$

and

$$
e^{i\left(\omega t-\epsilon_{z}\right)}=e^{i(\omega t-\epsilon)}
$$

Evaluation of the ex:itation forces in this form gives the maximum amplitude of the excitation for one wave and the phase relationship of this amplitude compared to the wave with its crest exactly admidships at the center of gravity. The excitation amplitudes $\mathrm{Z}_{1}, \mathrm{M}_{1}$ and $\mathrm{K}_{1}$ and the phase angles $\epsilon_{\mathrm{z}}, \epsilon_{\Theta}$ and $\epsilon_{\phi}$ have been calculated and are tabulated in Table 4 for each of the frequencies of interest. For comparison, the values of maximum generated wave amplitudes and phase angles measu $\cdot 1$ by Vugts $^{7}$ as a consequence of a known excitation of his model are also tabulat $\cdots$ in Table 4.

\subsection{Response Opcrators}

The equations of motion can now be solved for the desired variables $z_{\psi}=45$ degrees, $\Theta$ and $\phi$ for any wave length or frequency of regular wave. (Note: $\psi$ is the angle between the bow of the barge and the incoming component of the wave train.) The solution vectors will be of the form;

$$
r(t)=R_{r} \cos \left(\omega t+\delta_{r}\right)
$$

or

$$
r(t)=R_{r} e^{i\left(\omega t+\delta_{r}\right)}
$$

where $r$ represents any of the motions, $R_{r}$ is the magnitude of that motion or amplitude response operator, and $\delta_{r}$ is the phasing of the maximum possible motion relative to maximum positive wave displacement at amidships. ${ }_{r}$ is sometimes called the phase response operator. Thus for a unit wave amplitude, $r(t)$ is the 

response operator which is frequency dependent. The values of the motion response operators for heave, pitch and roll are listed in Table 5 and plotted as a function of $w$ in Figures 4,5 and 6.

Having calculated the motions, the vertical displacement, $\mathrm{Z}_{\mathrm{P}}$, velocity $\dot{\mathrm{Z}}_{\mathrm{P}}$, and acceleration, $\ddot{\mathrm{Z}}_{\mathrm{P}}$, of any point $\mathrm{P}=\left(\mathrm{x}_{\mathrm{P}}, \mathrm{y}_{\mathrm{P}}\right)$ can be calculated by coupling the motions from each component of the wave. Thus the vertical response operator of any point can be written as:

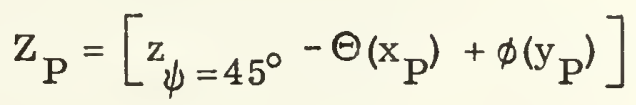

$$
\begin{aligned}
& \dot{\mathrm{z}}_{\mathrm{P}}=i \omega\left[\mathrm{z}_{\psi=45^{\circ}}-\Theta\left(\mathrm{x}_{\mathrm{P}}\right)+\phi\left(\mathrm{y}_{\mathrm{P}}\right)\right] \\
& \ddot{z}_{P}=-w^{2}\left[z_{\psi=45^{\circ}}-\Theta\left(x_{P}\right)+\phi\left(y_{P}\right)\right]
\end{aligned}
$$

It must be remembered that each of the response operators is a vector and thus must be added keeping track of all the phase response operators ${ }_{r}$. Figure 7 is an example phase diagram of this type of vector addition.

Since two of the four points of interest in deiurmining maximum acceleration includes a boom, the boom can be included in the response operators of equations (17), (18) and (19) by merely letting $x_{P}=1 \cos \alpha \cos \gamma$ and $y_{P}=1 \cos \alpha \sin \gamma$ where $l$ is the boom length, $\alpha$ is the elevation angle and $\gamma$ is the azimuth angle. Values for the response operator at the four points of interest are tabulated in Table 6.

\subsection{Description of the Seaway}

Since the response to any given wave frequency can now be calculated, it is necessary to apply the frequency spectra of an irregular sea using the energy density technique described by Loukakis $(1970)^{15}$ to predict the statistical properties of ship responses in a seaway. The spectral family that will be used to 

describe the seaway is the Pierson and Moskowitz (1963) ${ }^{16}$ family for a fully developed seaway. The general form of the spectral density function is given by

$$
Q(\omega)=\alpha \omega^{-5} \exp \left(-\beta \omega^{-4}\right)
$$

where $\mathrm{Q}(\omega)$ is the one sided spectral density function with units $\left(\mathrm{ft}^{2} \mathrm{x}\right.$ sec). The parameters $\alpha$ and $\beta$ for a fully developed sea are given by:

$$
\begin{aligned}
& \alpha=0.0081 \mathrm{~g}^{2}\left[\mathrm{ft} / \mathrm{sec}^{4}\right] \\
& \beta=0.0324 \mathrm{~g}^{2} /\left(\mathrm{H}^{\frac{1}{3}}\right)^{2} \quad\left[\mathrm{sec}^{-4}\right]
\end{aligned}
$$

where $\overline{\mathrm{H}}^{\frac{1}{3}}$ is the significant wave height which by definition equals four times the root mean square (rms) of the spectrum. Specific values for the spectral density function for three sea states at the frequencies of interest are tabulated in Table 7 along with corresponding wind speeds. 



\subsection{Response Spectra}

All absolute and relative barge motions, velocities and accelerations are nearly linear with respect to the wave. Thus the barge behaves approximately as a linear, time invariant filter and the output of the filter will have the same distribution as the input. If the sea spectral density function is plotted as proportional to $a^{2} / \delta w$ where a is the wave amplitude and $\delta \omega$ is an incremental frequency element and the barge response operator is plotted as proportional to $(\mathrm{z} / \mathrm{a})^{2}$, both as functions of $\omega$, it is clear that by the superposition principle:

$$
\frac{a^{2}}{\delta w} \times \frac{z^{2}}{a^{2}}=\frac{z^{2}}{\delta w}
$$

When $z^{2} / \delta w$ is plotted as a function of $\omega$, a response spectrum results. A quantity is now defined which is the average value of the response average over the frequency range. This average is obtained by integration over frequency or is the area of the spectrum. The root mean square, rms, of the response amplitude is then, $r m s=\sqrt{\text { area }}$, which represents a statistical average of the irregular random responses. From the rms value, other statistical averages such as the average value of the $1 / 3$ or $1 / 10$ highest response can be calculated by the relationship:

$$
\operatorname{Response}^{1 / \mathrm{N}}=\mathrm{f}_{1}(\mathrm{~N})(\mathrm{rms})
$$

The values of $N$ and $f_{1}(N)$ which are of interest in this study are listed in Table 8.

The values for calculated responses at the points of interest for the seven wave lengths investigated are tabulated in Table 9. These values were plotted and the area under the curve determined graphically. The rms values for each of the responses are listed in Table 10. 

TABIE 4

EXCITATION AMPLITUDES AND PHASE ANGIES
$\omega$
$2.01 \quad 1.42$
$1.16 \quad 1.00$
0.82
0.63
0.58

Amplitudes (Forces - 1 bf $\times 10^{3}$, Moments 1 bf-ft $\times 10^{3}$ )

$\begin{array}{lccccccc}\mathrm{Z}_{\boldsymbol{\omega}, \boldsymbol{\psi}=45^{\circ}} & 7.84 & 34.5 & 73.1 & 83.3 & 108.5 & 128.8 & 130.3 \\ \mathrm{Z}_{\boldsymbol{\omega}}(\text { Vugt s) } & & & & & & & \\ \mathrm{M}_{\boldsymbol{\omega}} & 51.5 & 82.1 & 96.6 & 107.8 & 116.0 & 124.0 & 128.7 \\ \mathrm{~K}_{\boldsymbol{\omega}} & 291 & 1610 & 1573 & 1358 & 1250 & 724 & 624 \\ \mathrm{~K}_{\omega} \text { (Vugts) } & 96 & 265 & 287 & 255 & 196 & 125 & 106\end{array}$

\section{Phase Angles (Degrees)}

$\begin{array}{lccccccc}\epsilon_{\mathrm{Z}}, \Psi=45^{\circ} & 113 & 233 & 216 & 212 & 203 & 195 & 193 \\ \epsilon_{\mathrm{Z}} \text { (Vugts) } & 135 & 75 & 40 & 30 & 25 & 20 & 10 \\ \epsilon_{\mathrm{M}} & 24 & 322 & 308 & 302 & 293 & 285 & 283 \\ \epsilon_{\mathrm{K}} & 90 & 270 & 270 & 270 & 270 & 270 & 270 \\ \epsilon_{\mathrm{K}} \text { (Vugts) } & 0 & 270 & 225 & \text { (remainder not mea sured) }\end{array}$



TABLE 5

MOTION RESPONSE OPERATORS
$\omega$
2.01
1.42
1.16
$1.00 \quad 0.82$
0.630 .58

Heave (ft/ft)

$\begin{array}{llllllll}\mathrm{z} / \mathrm{a} & 0.063 & 0.497 & 0.755 & 0.840 & 0.943 & 0.999 & 0.999\end{array}$

Pitch (Radians/ft $\times 10^{-3}$

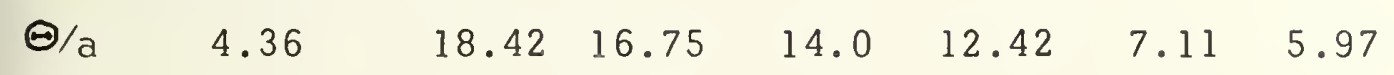

Roll (Radians/ft $\times 10^{-3}$

$\begin{array}{llllllll}\phi / \mathrm{a} & 1.28 & 3.43 & 3.60 & 3.16 & 2.40 & 1.52 & 1.28\end{array}$ 

Figure 4. Heave Response Operator

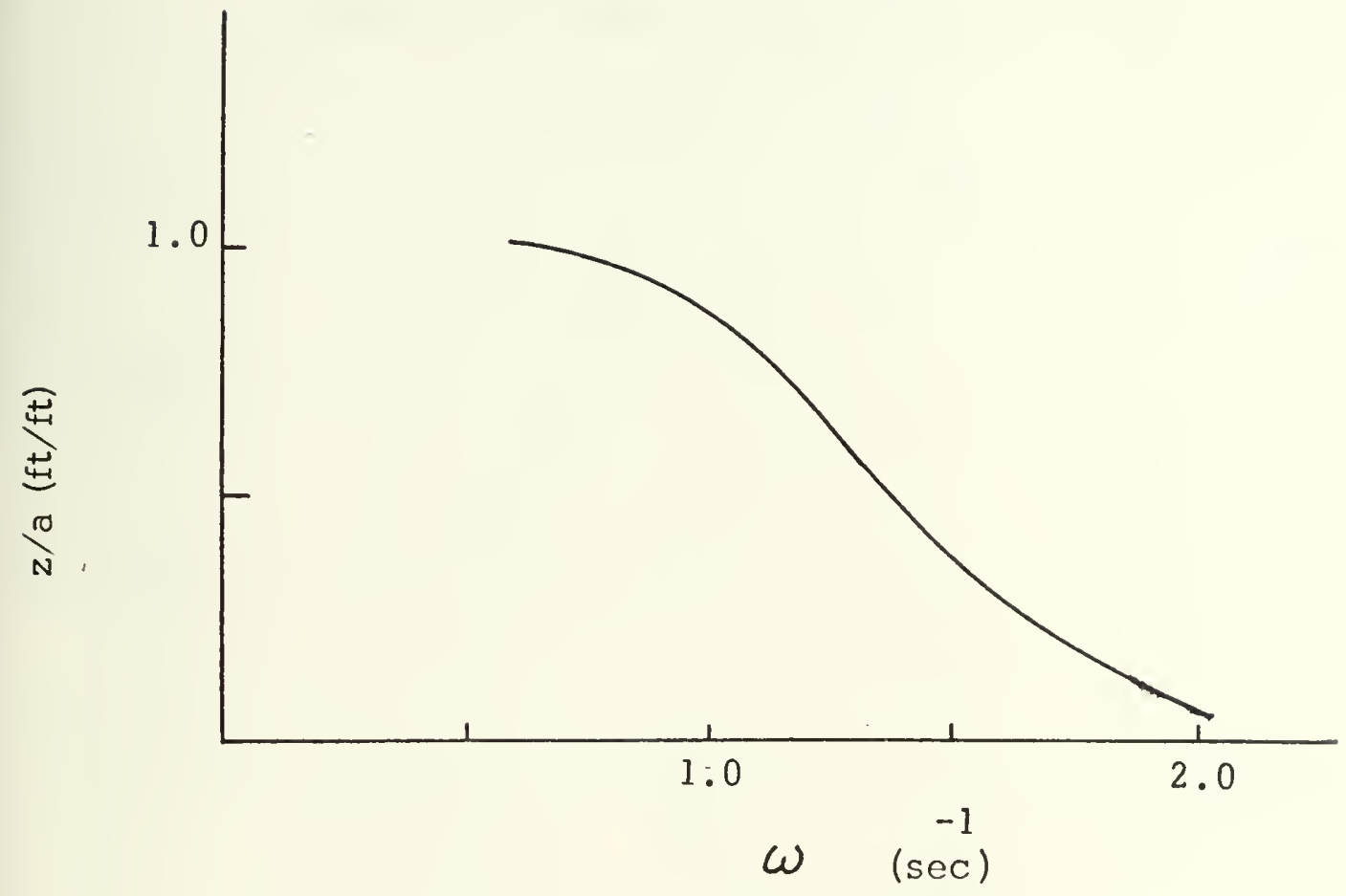

Figure 5. Pitch Response Operator

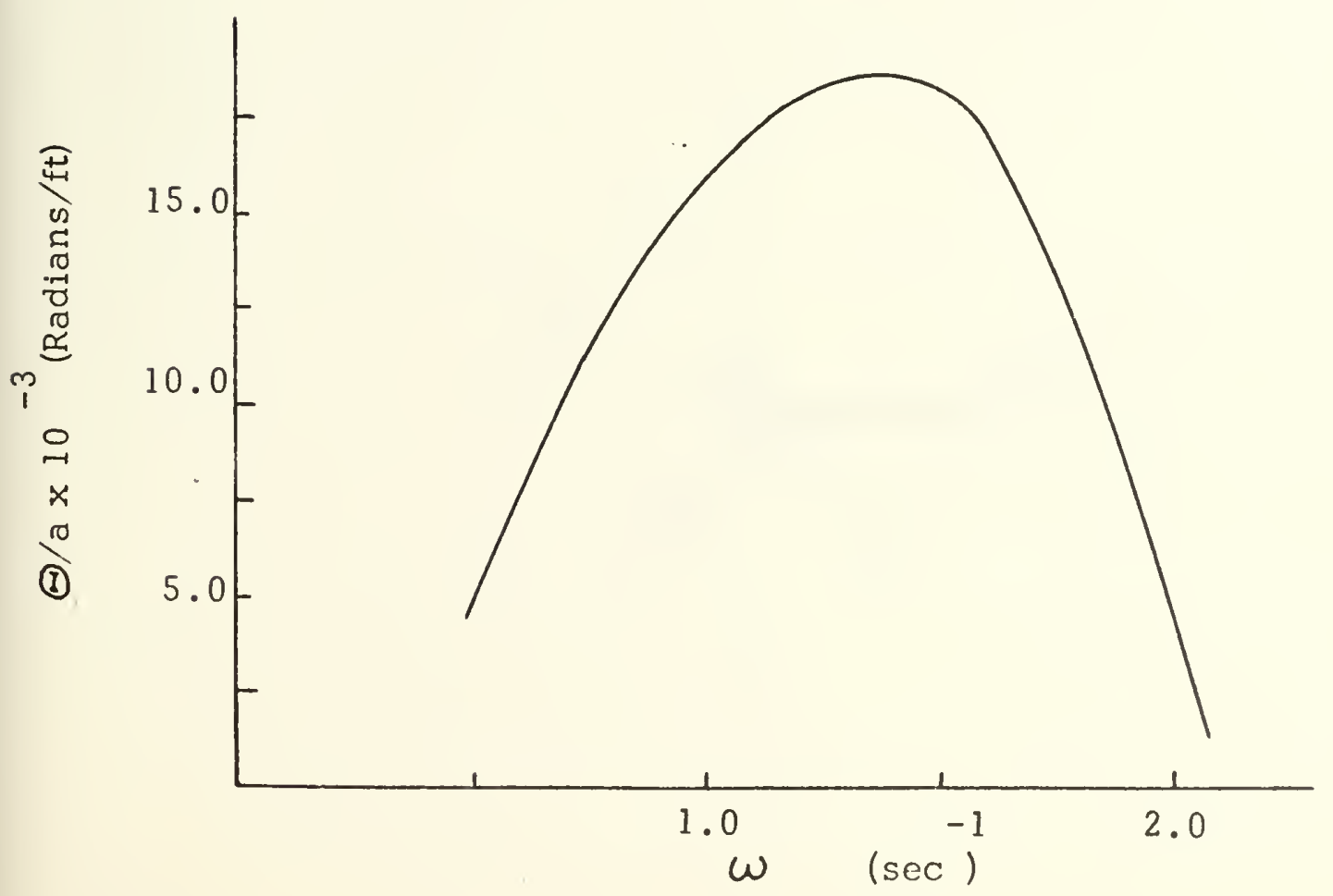



Figure 6. Roll Response Operator

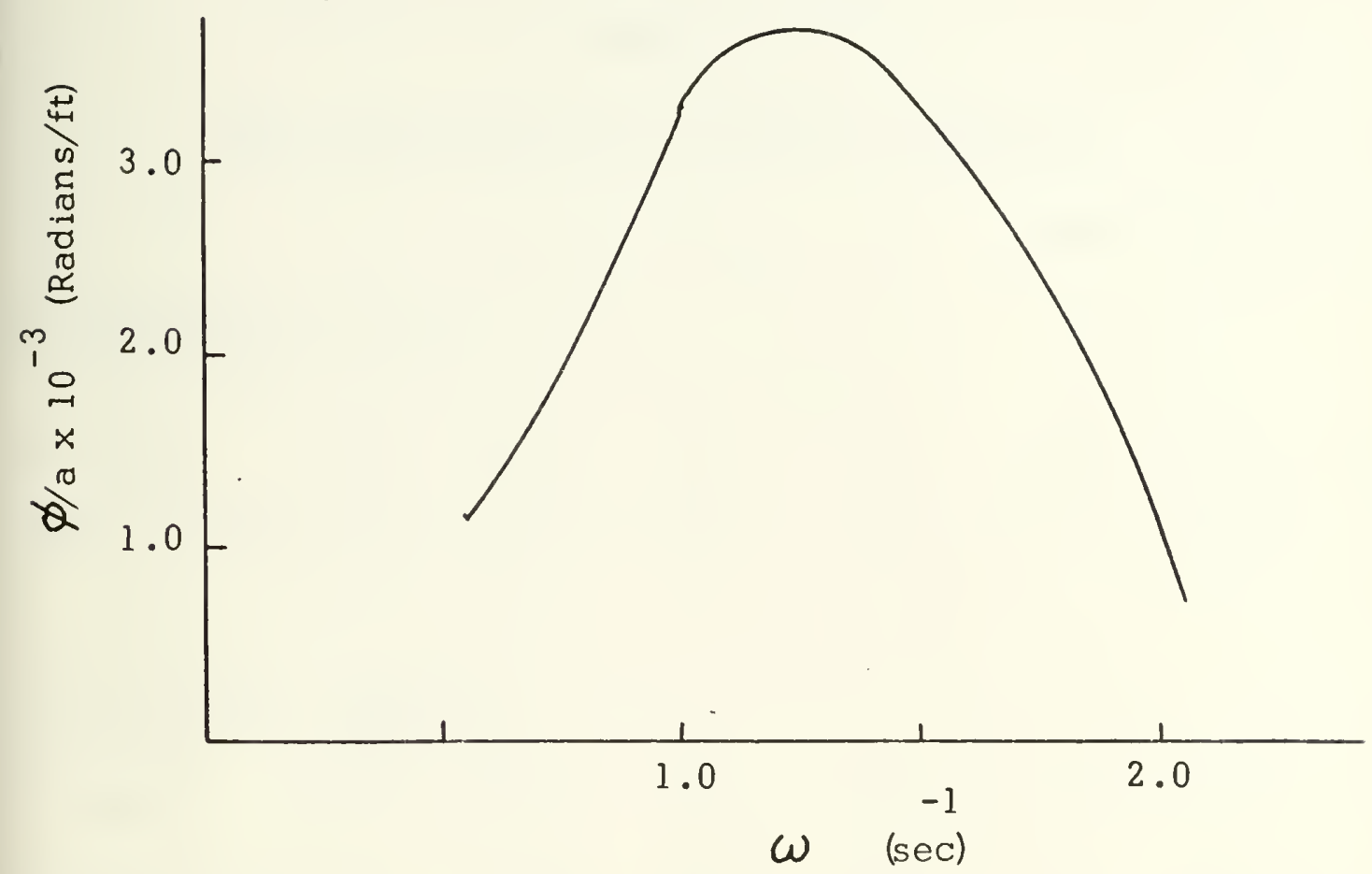

Figure 7. Sample Phase Diagram

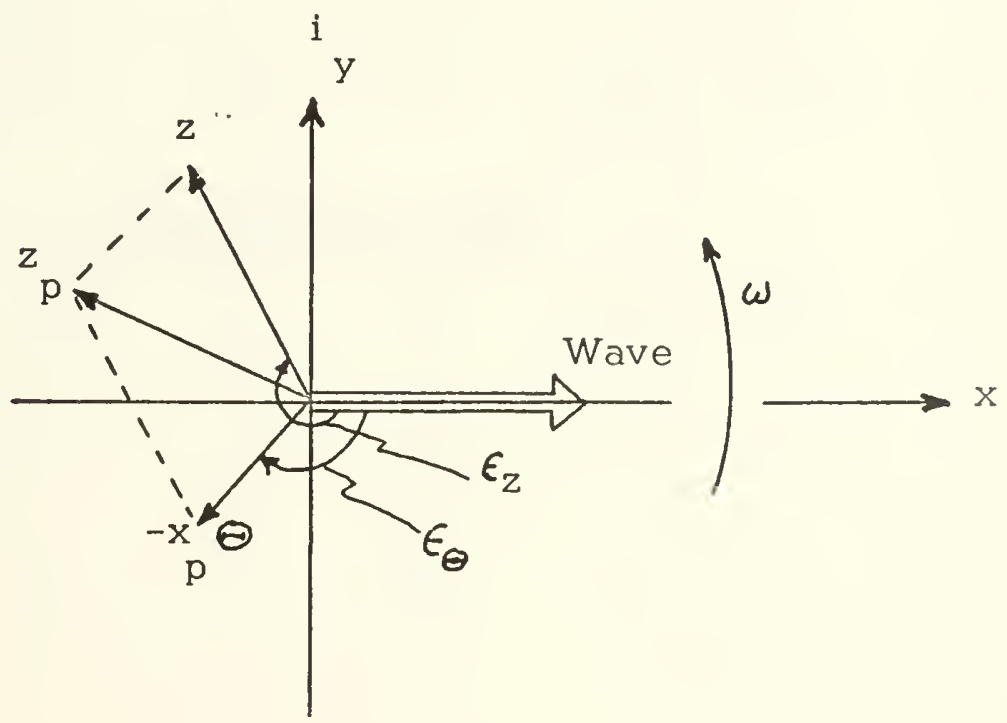





\section{TABLE 6}

RESPONSE OPERATOR AT POINTS OF INTEREST
$\omega$
$2.01 \quad 1.42$
$1.16 \quad 1.00$
0.82
0.63
0.58

Bow Amidships $(x=45 \mathrm{ft})$

$\mathrm{z} / \mathrm{a}(\mathrm{ft} \mathrm{ft})$

$0.22 \quad 0.92$

0.63

0.71

0.89

$0.97 \quad 0.97$

$\dot{z} \% \mathrm{a}\left(\mathrm{ft} / \mathrm{sec}^{2}-\mathrm{ft}\right) 0.90 \quad 1.84 \quad 0.85$

0.71

0.60

0.39

0.33

Stern Amidships $(x=-45 \mathrm{ft})$

$\begin{array}{lrrrrrrr}\mathrm{z} / \mathrm{a}(\mathrm{ft} / \mathrm{ft}) & 0.16 & 1.02 & 1.37 & 1.30 & 1.27 & 1.13 & 1.09 \\ \left.\dot{z} \% \mathrm{at} / \mathrm{sec}^{2}-\mathrm{ft}\right) 0.65 & 2.05 & 1.84 & 1.30 & 0.85 & 0.45 & 0.37\end{array}$

Boom at Port Beam (Boom $=60 \mathrm{ft}, \alpha=60^{\circ}, \gamma=-90^{\circ}$ )

$\begin{array}{llllllll}\mathrm{z} / \mathrm{a}(\mathrm{ft} / \mathrm{ft}) & 0.10 & 0.40 & 0.64 & 0.74 & 0.89 & 0.97 & 0.98\end{array}$

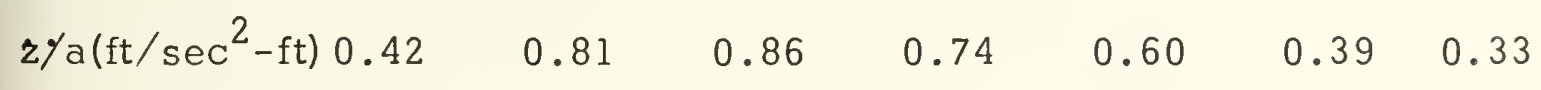

Boom Aft Port Bow (Boom $\left.=60 \mathrm{ft}, \underline{\propto}=60^{\circ}, \underline{\gamma}=-60^{\circ}\right)$

$\begin{array}{llllllll}\mathrm{z} / \mathrm{a}(\mathrm{ft} / \mathrm{ft}) & 0.10 & 0.23 & 0.54 & 0.66 & 0.82 & 0.93 & 0.95\end{array}$

$\begin{array}{lllllll}\dot{z} \% \mathrm{a}\left(\mathrm{ft} / \mathrm{sec}^{2}-\mathrm{ft}\right) 0.41 & 0.47 & 0.73 & 0.66 & 0.55 & 0.38 & 0.32\end{array}$ 

TABLE 7

PIERSON-MOSKOWITZ SPECTRAL DATA

FOR A FULLY DEVELOPED SEA

\section{Sea State Data}

\section{Sea State}

Wind Speed (KTS)

$\overline{\mathrm{H}}^{\frac{1}{3}}$ (ft)

$\alpha$

$\beta$

3

14.5

4

8.294

2.07
4

19.5

7

8.294

0.677

Spectral Density Function $\left(\mathrm{ft}^{2}-\mathrm{sec}\right)$

$\underline{\omega}$

$\mathrm{Q}_{3}(\omega)$

0.0018

0.0191

0.228

1.06

1.26

0.865

0.223

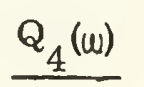

0.323

1.252

5.02

4.18

2.725

1.22

0.242
1.42

2.01
5

23.2

10

8.294

0.332

TABLE 8

VALUES FOR: RESPONSE ${ }^{1 / N}=f_{1}(N)(\mathrm{rms})$

\begin{tabular}{cc}
$\mathrm{N}$ & $\mathrm{f}_{1}(\mathrm{~N})$ \\
\hline 1 & 1.25 \\
3 & 2.00 \\
10 & 2.55 \\
$10^{2}$ & 3.34 \\
$10^{6}$ & 5.27
\end{tabular}



TABLE 9

RESPONSE SPECTRUM VALUES
$\omega 2.01$
1.42
1.16
1.00
0.82
0.63
0.58

\section{$\underline{\text { Sea State }}$}

Bow A midships - Displacement $z^{2} / \delta \omega\left(\mathrm{ft}^{2} / \mathrm{sec}\right)$

$\begin{array}{llllllll}3 & 0.011 & 0.73 & 0.50 & 0.55 & 0.20 & 0.018 & 0.017 \\ 4 & 0.012 & 1.02 & 1.09 & 2.13 & 4.48 & 1.18 & 0.31 \\ 5 & 0.012 & 1.12 & 1.31 & 2.99 & 9.60 & 9.87 & 6.37\end{array}$

Bow Amidships - A cceleration $\mathrm{z}^{2} / \delta \omega\left(\mathrm{ft}^{2} / \mathrm{sec}^{5}\right)$

$\begin{array}{llllllll}3 & 0.18 & 2.94 & 0.91 & 0.55 & 0.08 & 0.003 & 0.000 \\ 4 & 0.19 & 4.15 & 1.96 & 2.13 & 1.80 & 0.191 & 0.035 \\ 5 & 0.20 & 4.52 & 2.37 & 2.99 & 3.87 & 1.60 & 0.724\end{array}$

Stern Amidships - Displacement $z^{2} / \delta \omega$

$\begin{array}{llllllll}3 & 0.006 & 0.89 & 2.37 & 1.80 & 0.37 & 0.024 & 0.002 \\ 4 & 0.006 & 1.26 & 5.12 & 7.10 & 8.06 & 1.57 & 0.39 \\ 5 & 0.006 & 1.37 & 6.20 & 9.97 & 17.30 & 13.27 & 8.10\end{array}$

Stern Amidships - Acceleration $\mathrm{z}^{2} / \delta \omega$

$\begin{array}{llllllll}3 & 0.090 & 3.62 & 4.26 & 1.80 & 0.17 & 0.004 & 0.000\end{array}$

$\begin{array}{llllllll}4 & 0.101 & 5.10 & 9.28 & 7.10 & 3.64 & 0.258 & 0.044\end{array}$

$\begin{array}{llllllll}5 & 0.103 & 5.56 & 11.16 & 9.97 & 7.79 & 2.065 & 0.916\end{array}$ 
TABLE 9 (Cont'd.)

RESPONSE SPECTRUM VALUES
$\omega 2.01$
1.42
1.16
1.00
0.82
0.63
0.58

Boom at Port Beam - Displacement $z^{2} / \delta \omega$

$\begin{array}{llllllll}3 & 0.092 & 0.14 & 0.51 & 0.55 & 0.18 & 0.018 & 0.002\end{array}$

$\begin{array}{llllllll}4 & 0.003 & 0.20 & 1.11 & 2.19 & 3.94 & 1.19 & 0.311\end{array}$

$\begin{array}{llllllll}5 & 0.003 & 0.22 & 1.34 & 3.08 & 8.45 & 9.97 & 6.52\end{array}$

\section{Sea State}

Boom at Port Beam - Acceleration $\ddot{z}^{2} / \delta \omega$

$\begin{array}{llllllll}3 & 0.040 & 0.57 & 0.92 & 0.55 & 0.081 & 0.002 & 0.000 \\ 4 & 0.043 & 0.81 & 2.00 & 2.19 & 1.78 & 0.19 & 0.035 \\ 5 & 0.044 & 0.88 & 2.42 & 3.08 & 3.81 & 1.62 & 0.74\end{array}$

Boom Aft Port Bow - Displácement $z^{2} / \delta \omega$

$\begin{array}{llllllll}3 & 0.002 & 0.046 & 0.37 & 0.47 & 0.15 & 0.017 & 0.002\end{array}$

$\begin{array}{llllllll}4 & 0.003 & 0.066 & 0.79 & 1.84 & 3.38 & 1.09 & 0.29\end{array}$

$\begin{array}{llllllll}5 & 0.003 & 0.071 & 0.97 & 2.58 & 7.25 & 9.15 & 6.07\end{array}$

Boom Aft Port Bow - Acceleration $z^{2} / \delta \omega$

$\begin{array}{llllllll}3 & 0.037 & 0.19 & 0.67 & 0.47 & 0.069 & 0.003 & 0.000\end{array}$

$\begin{array}{llllllll}4 & 0.040 & 0.26 & 1.43 & 1.84 & 1.53 & 0.178 & 0.033\end{array}$

$\begin{array}{llllllll}5 & 0.041 & 0.29 & 1.74 & 2.58 & 3.27 & 1.49 & 0.68\end{array}$ 

TABLE 10

RESPONSE RMS VALUES

\section{$\underline{\text { Sea State }}$}

Location

$\begin{array}{llll}\text { Motion } & \underline{3} & \underline{4} & \underline{5} \\ \mathrm{Z} \mathrm{ft} & 0.75 & 1.35 & 2.16\end{array}$

Bow Amidships

$$
\begin{array}{llll}
\ddot{\mathrm{Z}} \mathrm{ft} / \mathrm{sec} & 1.24 & 1.61 & 1.95 \\
\mathrm{Z} & 1.09 & 2.04 & 3.13
\end{array}
$$

Stern Amidships

$\begin{array}{llll}\ddot{Z} & 1.57 & 2.37 & 2.74 \\ \mathrm{Z} & 0.53 & 1.25 & 2.02\end{array}$

Boom at Port Beam

$\begin{array}{llll}\ddot{Z} & 0.71 & 1.19 & 1.57 \\ . . & & & \\ Z & 0.44 & 1.13 & 1.92\end{array}$

Boom Aft Port Bow
$\dot{\mathrm{Z}}^{\bullet}$
$\begin{array}{lll}0.57 & 0.99 & 1.32\end{array}$ 

4. Discussion of Results

\subsection{Response Operators}

The response operator amplitudes for heave, pitch and roll have been presented in Table 5 and Figures 4,5 and 6 . The heave operator behaves as expected approaching a maximum value of the wave amplitude. The pitch operator is slightly lower than the maximum wave slope at the low frequencies. If the maximum wave slope is given by $\frac{2 \pi \mathrm{a}}{\lambda}$, then at $\lambda=600 \mathrm{ft}$, the slope would be only about $1.05 \times 10^{-2}$ (Radians/Unit amplitude). The values of the operator are in general agreement with the values found by Kaplan and Putz ${ }^{13}$ for CUSS I. The roll operator behaves as ecpected but is about an order of magnitude lower than values determined by Kaplan and Putz. It should be mentioned that CUSS I has a more ship type hull than the crane barge. The roll coefficients of Vugts ${ }^{7}$ also had considerable spread in the data which may account for the difference.

\subsection{Response Operators at Points of Interest}

The response operator amplitudes for vertical displacement and acceleration for the four points of interest have been presented in Table 6. The values for bow and stern amidships reflect the coupling of pitch and heave. The contribution of roll to the motion 

of the crane boom was fairly small compared to pitch and heave due again to the small value of the response operator.

\subsection{RMS Values}

The results of the spectral analysis were presented in Table 10 in the form of rms values for vertical displacements and accelerations. The value for displacement in sea states 3 and 4 is felt to be accurate, however sea state 5 had significant contribution between 1.42 and 2.01 radians where the shape of the curve was not calculated. The accelerations are more accurate however since the values at both ends of the frequency span chosen are negligible. All of the rms values would have been more accurate with more points, especially at the low end of the frequency scale and between $\omega=2.01$ and $\omega=1.42$.

\subsection{Limitation on Operations}

Now that the rms amplitude values of verticle di splacement and acceleration are known, the probability of having a total response of any magnitude can be calculated from equation (23). For example, for sea state 4 the rms of the displacement amplitude at the bow is 1.35 ft. Using Table 8 , for $66.7 \%$ of the time, the displacement would be less than about $2.7 \mathrm{ft}$. Only one displacement in 100 would exceed $4.5 \mathrm{ft}$ and one in one million would exceed $7.1 \mathrm{ft}$. Since the average period of sea state 4 in this study is about 5 seconds, this means that 

the occurrence of an excitation which would produce a displacement response greater than $7.1 \mathrm{ft}$ would be only once in a time period of about 58 days. Based on this type of analysis, the displacements and accelerations received as a result of sea state 4 are too large for anything but very short mission duration weight handling. Sea state $3 \mathrm{rms}$ values of this study should be satisfactory for operations when synthetic line and the leithiser constant tension winch are used to compensate for part of the displacement and acceleration.

\section{Conclusions and Recommendations}

It appears that the operational limitation on Project AFAR to sea state 3 on the Beaufort scale was a bit conservative since this corresponds to a wind speed of 10 knots whereas the Pierson-Moskowitz sea state 3 of this study corresponds to a wind speed of 14.5 knots. Operations in this latter sea state should be acceptable if the Leithiser constant-tension winch is used with synthetic line to compensate for the motions. For sea state 4 of this study, the probability of exceeding the capability of the weight handling system is great enough that operations would be limited to very short load lifting missions at best.

It is recommended that this method of analysis be reduced to a computer program for all heading angles at more frequency points to provide more accurate $\mathrm{ms}$ values. It is also recommended that more research be done on refining the hydrodynamic coefficients for roll for shallow draft box shaped hulls to eliminate the uncertainties in the data of Vugts. 



\section{REFERENCES}

1. NCEL Report TR-543 "Mechanics of Raising and Lowering Heavy Loads in the Ocean: Experimental Results", Muga, B.J. Sept 1967.

2. NCEL Report TR-652 "Feasibility Study and Comparative Analysis of Deep Ocean Load Handling Systems" by Davis, D. A. and Wolfe, M. J. Dec 1969.

3. NCEL Report TR-703 "Dynamic Stress Response of Lifting Lines for Oceanic Operations" by Liu, C.L. Nov 1970.

4. Korvin - Kroukovsky, B.V. "Investigation of Ship Motions in Regular Waves," Transactions of the Society of Naval Architects and Marine Engineers, Vol 63, pp. 386-435 (1955).

5. Naval Facilities Engineering Command, Project AFAR(AUTEC), Management/ Operation Plan 1/27/70.

6. NCEL Technical Report R-440, "Hydrodynamic Analysis of a Spread-Moored Platform in the Open Sea"., Muga, B.J. Aug 1966.

7. Laboratorium Voor Scheepsbouwkunde Report No. 194 "The Hydrodynamic Coefficients for Swaying, Heaving and Rolling Cyclinders in a Free Surface" by Vugts, J.H. Jan $1: 38$.

8. Abkowitz, M. A. "Stability and Motion Control of Ocean Vehicles" MIT Press (1969).

9. Abkowitz, M.A., Vossilopolous, L.A., and Sellers, F.H. "Recent Development in Seakeeping Research and its Applications',, Trans SNAME, Nov 1966.

10. Mandel, P. "Principles of Naval Architecture - Ship Maneuvering and Control", SNAME 1967.

11. Korvin-Kroukovsky, B.V. "Theory of Seakeeping" SNAME 1961.

12. Lewis, E. V. "Principles of Naval Architecture - The Motion of Ships in Waves", SNAME 1967.

13. Kaplan, P and Putz, R.R., "The Motions of a Moored Construction Type Barge in Irregular Waves and Their Influence on Construction Operations", NCEL Contract NBY-32206, August 1962.

14. NSRDC Report 2375, "Oscillation of Cylinders in or Below the Free Surface of of Deep Fluids", Frank, W., October 1967. 



\section{REFERENCES (Cont'd.)}

15. MIT Report 70-3, "Computer Aided Prediction of Seakeeping Performance in Ship Design", Loukakis, T.A., August 1970.

16. Pierson, W.J. and Moskowitz, L., "A Proposed Spectral Form Based on the Simularity Theory of S.A. Kilaigorodski", Geophysical Sciences Laboratory, Report No 63-12, N.Y. University, (1963).

17. Vossers, G. (1960) "Fundamentals of the Behavior of Ships in Waves", International Shipbuilding Progress, Vol 7, No. 65, Jan 1960. 



\section{APPENDIX A}

\section{EVALUATION OF THE HYDRODYNAMIC COE FFICIENTS}

\section{A1 Inertial Coefficients}

The coefficients of the accelleration terms are the result of the hydrodynamic forces and moments caused in reaction to the accelleration of a body through the water they are negative in value and thus add to the mass a inertia of the body. A1. I Heave Added Mass, $\mathrm{Z}_{\dot{\mathrm{w}}}$ and $\mathrm{Z}_{\dot{\mathrm{q}}}$

$\mathrm{Z}_{\dot{\mathrm{w}}}$ is the added mass in heave which is in phase with the verticle accelleration in equation (1) while $\mathrm{Z}_{\dot{\mathrm{q}}}$ is the added inertia in phase with the angular accelleration of pitch. Muga ${ }^{6}$ defined these coefficients over a unit section of ship length as:

$$
\begin{aligned}
& \mathrm{Z}_{\dot{\mathrm{w}}}=-\int_{\xi_{\mathrm{S}}}^{\xi_{\mathrm{b}}} \frac{\mathrm{C}}{2} \frac{\rho \mathrm{B}^{*}}{4} \mathrm{~d} \xi \\
& \mathrm{Z}_{\dot{\mathrm{q}}}=\int_{\xi_{\mathrm{S}}}^{\xi_{\mathrm{b}}} \mathrm{Z}_{\dot{\mathrm{w}}} \xi \mathrm{d} \xi
\end{aligned}
$$

where $\mathrm{B}^{*}$ is the sectional beam, C is a frequency dependent correction factor, and $\xi$ is a cummy variable along the $x$-axis which is integrated from the stem, $\xi_{\mathrm{S}}$, to the bow $\xi_{\mathrm{b}}$. The limits of integration will be deleted in future integrals unless they differ from the above. It should be noted that due to $\mathrm{Z}_{\mathrm{W}}$ being constant for each section, the coupled pitch-heave added mass, $\mathrm{Z}_{\dot{q}}$, will be zero for all frequencies. The values calculated by equation 24 ) for $\mathrm{Z}_{\mathrm{w}}$ are tabulated in Table 2 along with the comparable experimentally determined values of Vugts.

A1.2 Pitch Added Inertia, $M_{\dot{w}}$ and $M_{\dot{q}}$

These derivatives are in phase with the verticle accelleration and pitch angular accelleration and have been defined by Muga ${ }^{6}$ as: 



$$
\begin{aligned}
& \mathrm{M}_{\dot{\mathrm{w}}}=\int \mathrm{z}_{\dot{\mathrm{w}}} \xi \mathrm{d} \xi \\
& \mathrm{M}_{\dot{\mathrm{q}}}=\int \mathrm{z}_{\dot{\mathrm{w}}} \xi^{2} \mathrm{~d} \xi
\end{aligned}
$$

For the same reasons as expressed for $\mathrm{Z}_{\dot{q}}$ in equation (25), $\mathrm{M}_{\dot{\mathrm{W}}}$ is also equal to zero. The values of $M_{\dot{q}}$ calculated from equation (27) are listed in Table 2 along with the experimental values of Vugts. ${ }^{7}$

A1.3 Roll Added Inertia, $\mathrm{K}_{\dot{\mathrm{p}}}$

Muga calculated $\mathrm{K}_{\mathrm{p}}$ from the effective radius of gyration, $\mathrm{k}_{\mathrm{e}}$, by the relationship:

$$
\mathrm{mk}_{\mathrm{e}}^{2}=\left(\mathrm{I}_{\mathrm{xx}}-\mathrm{K}_{\dot{\mathrm{p}}}\right)
$$

The effective radius of gyration was calculated from the experimentally determined roll natural period of FISH HOOK by the relationship:

$$
T=\frac{2 \pi k_{e}}{[g(G \bar{M})]^{\frac{I}{2}}}
$$

Since the natural roll period of the AFAR crane barge is not known with any accu racy, only the experimental values of $\mathrm{K}_{\mathbf{p}}$ determined by Vugts are listed in Table 2.

A2 Dynamic Damping Coefficients

The hydrodynamic damping forces and moments are in phase with the body velocity and are proportional to the dissapated wave energy. Viscous effects of the fluid have been neglected in this study. Thus the damping coefficients are the coefficients of the velocity terms of the equations of motions. 



\section{A2. 1 Heave Damping, $\mathrm{Z}_{\mathrm{w}}$ and $\mathrm{z}_{\mathrm{q}}$}

Muga ${ }^{6}$ derived the heave damping coefficients as follows:

$$
\begin{gathered}
\mathrm{z}_{\mathrm{w}}=-\mathrm{C}_{\mathrm{zz}} \int \frac{\rho \mathrm{g}^{2}\left(\overline{\mathrm{A}}_{\mathrm{z}}\right)^{2}}{w^{3}} \mathrm{~d} \xi \\
\mathrm{z}_{\mathrm{q}}=\mathrm{C}_{\mathrm{z} \Theta} \int \frac{\rho \mathrm{g}^{2}\left(\overline{\mathrm{A}}_{\mathrm{z}}\right)^{2}}{\omega^{3}} \xi \mathrm{d} \xi ; \mathrm{C}_{\mathrm{z} \Theta}=1
\end{gathered}
$$

where $\bar{A}_{z}$ is the ratio of the amplitude of the heave generated two dimensional waves to the heaving motion of the section and $\mathrm{C}_{\mathrm{zz}}$ and $\mathrm{C}_{\mathrm{z} \Theta}$ are three dimensional damping factors. Again because of the constant sectional coefficient, $z_{q}$ is equal to zero in equation (31). The values of $\mathrm{Z}_{w}$ calculated by equation (30) are compared with the experimental values of $\mathrm{Vu}_{\mathrm{s} t \mathrm{~s}}{ }^{7}$ in Table 2 .

\section{A2.2 Pitch Damping, $\mathrm{M}_{\mathrm{w}}$ and $\mathrm{M}_{\mathrm{q}}$}

These coefficients in phase with the verticle velocity and the pitch velocity are defined by Muga ${ }^{6}$ as:

$$
\begin{gathered}
M_{w}=C_{\Theta z} \int \frac{\rho g\left(\bar{A}_{z}\right)^{2}}{w^{3}} \xi d \xi ; C_{\Theta z}=C_{z \Theta}=1 \\
M_{q}=-C_{\Theta \Theta} \int \frac{\rho g\left(\bar{A}_{z}\right)^{2}}{w^{3}} \xi^{2} d \xi ; C_{\Theta \Theta}=C_{z z}
\end{gathered}
$$

$I_{w}$ is once again equal to zero due to the coefficient being constant over the length f the body. The values of $\mathrm{M}_{\mathrm{q}}$ calculated from equation (33) are compared to the xperimental values of Vugts in Table 2. 

A2. 3 Roll Damping, $\mathrm{K}_{\mathrm{p}}$

Muga derives the roll damping coefficient as:

$$
K_{p}=-C_{y y}(\overline{B G})^{2} \frac{\rho \omega}{4} \int B *^{2}\left(d_{y}\right)^{2} d \xi
$$

where $\mathrm{d}_{\mathrm{y}}$ is a correction coefficient which is a function of sectional area and beamdraft ratio derived by Vossers (1960) ${ }^{17}$. The values of $K_{p}$ calculated by equation (34) are compared with those determined by Vugts ${ }^{7}$ in Table 2. The large difference between the calculated and the experimental values should be noted. Muga's assumption of transverse damping force times the moment arm is not very valid. Therefore, the values determined by Vugts will be used in the solution of the equation of motion.

\section{A3 Hydrostatic Coefficients}

The hydrostatic coefficients are easily calculable and are independent of frequency.

A3.1 Heave, $\mathrm{Z}_{\mathrm{z}}$ and $\mathrm{Z}_{\Theta}$

The hydrostatic heave and coupling coefficients are:

$$
\begin{aligned}
& Z_{z}=-\rho g \int B^{*} d \xi \\
& Z_{\Theta}=\rho g \int B^{*} \xi d \xi
\end{aligned}
$$

Due to constant beam, the value of the coupling coefficient, $\mathrm{z}_{\Theta}$, is zero. 

A3.2 Pitch, $\mathrm{M}_{\mathrm{z}}$ and $\mathrm{M}_{\Theta}$

The hydrostatic pitch and coupling coefficients then are given by:

$$
\begin{aligned}
& \mathrm{M}_{\mathrm{z}}=\rho \mathrm{g} \int \mathrm{B}^{*} \xi \mathrm{d} \xi \\
& \mathrm{M}_{\Theta}=-\rho \mathrm{g} \int \mathrm{B}^{*} \xi^{2} \mathrm{~d} \xi
\end{aligned}
$$

where $\mathrm{M}_{\mathrm{z}}$ is also equal to zero

\section{A3. 3 Roll, $\mathrm{K}_{\phi}$}

The roll hydrostatic coefficient is given by the relation:

$$
\mathrm{K}_{\phi}=-\rho \mathrm{g} \nabla|\overline{\mathrm{GM}}|
$$

or

$$
\mathrm{K}_{\phi}=-\Delta|\overline{\mathrm{GM}}|
$$

where $\nabla$ is the immersed volume of the barge and $\Delta$ is the barge displacement.

\section{A3. 4 Values}

Calculated values for the hydrostatic coefficients are listed in Table 3 in dimensional form for use in solving the equations of motions. 



\section{APPENDIX B}

\section{WAVE EXCITATION FORCES AND MOMENTS}

\section{B1 General Description}

The wave surface elevation of a unidirectional train of regular waves in deep water is defined as:

$$
\eta(x, t)=a \cos \left(\frac{2 \pi x}{\lambda}-\omega t+\epsilon\right)
$$

where:

$\omega=\sqrt{\frac{2 \pi g}{\lambda}}$ Angular frequency of the wave

$\mathrm{a}=$ Wave amplitude

$\mathrm{x}=$ Distance along direction of wave travel

$\lambda=$ Wave lengtl: in direction of wave travel

$\epsilon=$ Phase at origin when $\mathrm{t}=0$, (zero in this case)

The wave induced excitation forces and moments are given by:

$$
\begin{gathered}
F_{j} e^{i\left(\omega t-\epsilon_{j}\right)}=\int_{\text {stern }}^{\text {Bow }} \frac{d F_{j}}{d x} d x \\
\cdot \\
M_{j} e^{i\left(\omega t-\epsilon_{j}\right)}=-\int_{\text {stern }}^{\text {Bow }} \frac{d F_{j}}{d x} x d x
\end{gathered}
$$

The general form of the sectional wave induced force is given by:

$$
\begin{aligned}
\frac{d F_{j}}{d x}= & {\left[\rho g B^{*}(x) \eta(x, t)+N_{j}(x) \dot{\eta}(x, t)\right.} \\
& \left.+\mu_{j}(x) \ddot{\eta}(x, t)\right] \exp \left(-\frac{2 \pi H(x)}{\lambda}\right)
\end{aligned}
$$



where:

$$
\begin{aligned}
& N_{j}(x)=\text { Sectional damping }\left[1 b f-s e c / f t^{2}\right] \\
& \mu_{j}(x)=\text { Sectional added mass }[\text { slugs } / f t]
\end{aligned}
$$

The specific forces and moments can now be developed in terms of the hydrodynamic coefficients derived in Appendix A.

\section{B2 Heave Excitation}

The heave wave forces will be broken down into two components, one approaching the barge from head-on along the $\mathrm{x}$-direction and the other from beam-on along the $y$-direction. The sectional hydrodynamic coefficient is found by dividing the total coefficient of Table 2 by the barge length since the sectional coefficients are constant over the length. The limits of all integrals will be from $-\mathrm{L} / 2$ to $\mathrm{L} / 2$ unless otherwise noted and the limits will be deleted in future equations where the meaning is clear.

The general expression for the surface elevation of the waves, equation (41) has been modified to account for the two components of the incoming wave as follows :

$$
\eta(x, y, t)=a \cos \left(\frac{2 \pi x \cos \psi}{\lambda}+\frac{2 \pi y \sin \psi}{\lambda}-\omega t\right)
$$

where $\psi$ is the angle between the barge heading and the direction of the incoming wave, $45^{\circ}$ in this study. Then the general expression for the heave excitation is:

$$
\begin{aligned}
Z_{\omega, \psi=45^{\circ}=} & a \exp \left(-\frac{2 \pi H}{\lambda}\right) \int_{-B / 2}^{B / 2} \int_{-L / 2}^{L / 2}\left\{\left[\frac{Z}{L B}-\omega^{2} \frac{Z \dot{W}}{L B}\right] \cos \left(\frac{2 \pi x}{\sqrt{2 \lambda}}+\frac{2 \pi y}{\sqrt{2 \lambda}}-\omega t\right)\right. \\
& \left.+\omega \frac{Z w}{L B} \sin \left(\frac{2 \pi x}{\sqrt{2} \lambda}+\frac{2 \pi y}{\sqrt{2} \lambda}-\omega t\right)\right\} d x d y
\end{aligned}
$$



Integrating this equation gives:

$$
\begin{aligned}
& \mathrm{Z}_{\mathrm{w}, \psi=45^{\circ}}=\left(\frac{\sqrt{2} \lambda}{2 \pi}\right)^{2} \text { a } 4 \sin \frac{\pi \mathrm{L}}{\sqrt{2 \lambda}} \sin \frac{\pi \mathrm{B}}{\sqrt{2 \lambda}} \exp \left(-\frac{2 \pi \mathrm{H}}{\lambda}\right)\left\{\left[\frac{\mathrm{Z}}{\mathrm{LB}}-\omega^{2} \frac{\mathrm{Z} \dot{\mathrm{w}}}{\mathrm{LB}}\right] \cos \omega \mathrm{t}\right. \\
& \left.-w \frac{\mathrm{Z}}{\mathrm{LB}} \sin \omega t\right\}
\end{aligned}
$$

B3 Pitch Excitation

The general equation for the pitch excitation is:

$$
\begin{aligned}
M_{w}= & {\left[a \frac{Z}{L} \int-x \cos \left(\frac{2 \pi x}{\sqrt{ } 2 \lambda}-\omega t\right) d x+a \omega \frac{\text { Z }}{L} \int-x \sin \left(\frac{2 \pi x}{\sqrt{ } 2 \lambda}-\omega t\right) d x\right.} \\
& \left.-a \omega^{2} \frac{Z^{\frac{\dot{w}}{w}}}{L} \int-x \cos \left(\frac{2 \pi x}{\sqrt{ } 2 \lambda}-\omega t\right) d x\right] \exp \left(-\frac{2 \pi H}{\lambda}\right)
\end{aligned}
$$



Integrating this equation gives:

$$
\begin{aligned}
M_{\omega}= & \frac{\sqrt{2} \lambda}{2 \pi} a\left[\frac{2}{2 \pi} \sin \frac{\pi L}{\sqrt{2} \lambda}-L \cos \frac{\pi L}{\sqrt{2} \lambda}\right] \exp \left(-\frac{2 \pi H}{\lambda}\right)\left\{\left[\omega{ }^{2} \frac{Z_{W}}{L}-\frac{Z}{L}\right] \sin \omega t\right. \\
& \left.-\omega \frac{Z_{w}}{L} \cos \omega t\right\}
\end{aligned}
$$

B4 Roll Excitation

Only two components of the roll excitation will be considered since the damping excitation is known to be quite small. The effect of head-on waves has been neglected. The only inertial component that will be included is due to the shift of the center of buoyancy from the $z$-axis in a $\pm y$ direction creating a moment arm for the buoyancy of each section as the wave passes. The hydrostatic component used was derived by Muga ${ }^{6}$. The general expression for beam-on waves is:

$$
\mathrm{K}_{\omega}=-\rho \omega^{2} \mathrm{a} \exp \left(-\frac{2 \pi \mathrm{H}}{\lambda}\right)\left[\int \overline{\mathrm{Y}}_{\mathrm{CB}} \mathrm{Sdx}+\int \frac{\mathrm{B}^{3}}{12} \sin \left(\frac{2 \pi \mathrm{x}}{\sqrt{2} \lambda}-\omega t\right) \mathrm{dx}\right] .
$$

where: $\mathrm{Y}_{\mathrm{CB}}$ is the motion of the ceriter of buoyancy in the $\mathrm{y}$-direction and $\mathrm{S}$ is the sectional area under the wave. Integration of equation $(50)$ gives:

$$
\begin{aligned}
\mathrm{K}_{\omega}= & -\rho \omega^{2} \mathrm{a} \exp \left(-\frac{2 \pi \mathrm{H}}{\lambda}\right)\left\{\mathrm{L} a \frac{\sqrt{2} \lambda}{2 \pi}\left[\frac{\sqrt[2]{2} \lambda}{2 \pi} \sin \frac{\pi \mathrm{B}}{\sqrt{2} \lambda}-\mathrm{B} \cos \frac{\pi \mathrm{B}}{\sqrt{2} \lambda}\right]\right. \\
& \left.+\frac{\mathrm{B}^{3}}{12} \frac{\sqrt{2} \lambda}{2 \pi} 2 \sin \frac{\pi \mathrm{L}}{\sqrt{2} \lambda}\right\} \sin \omega \mathrm{t}
\end{aligned}
$$







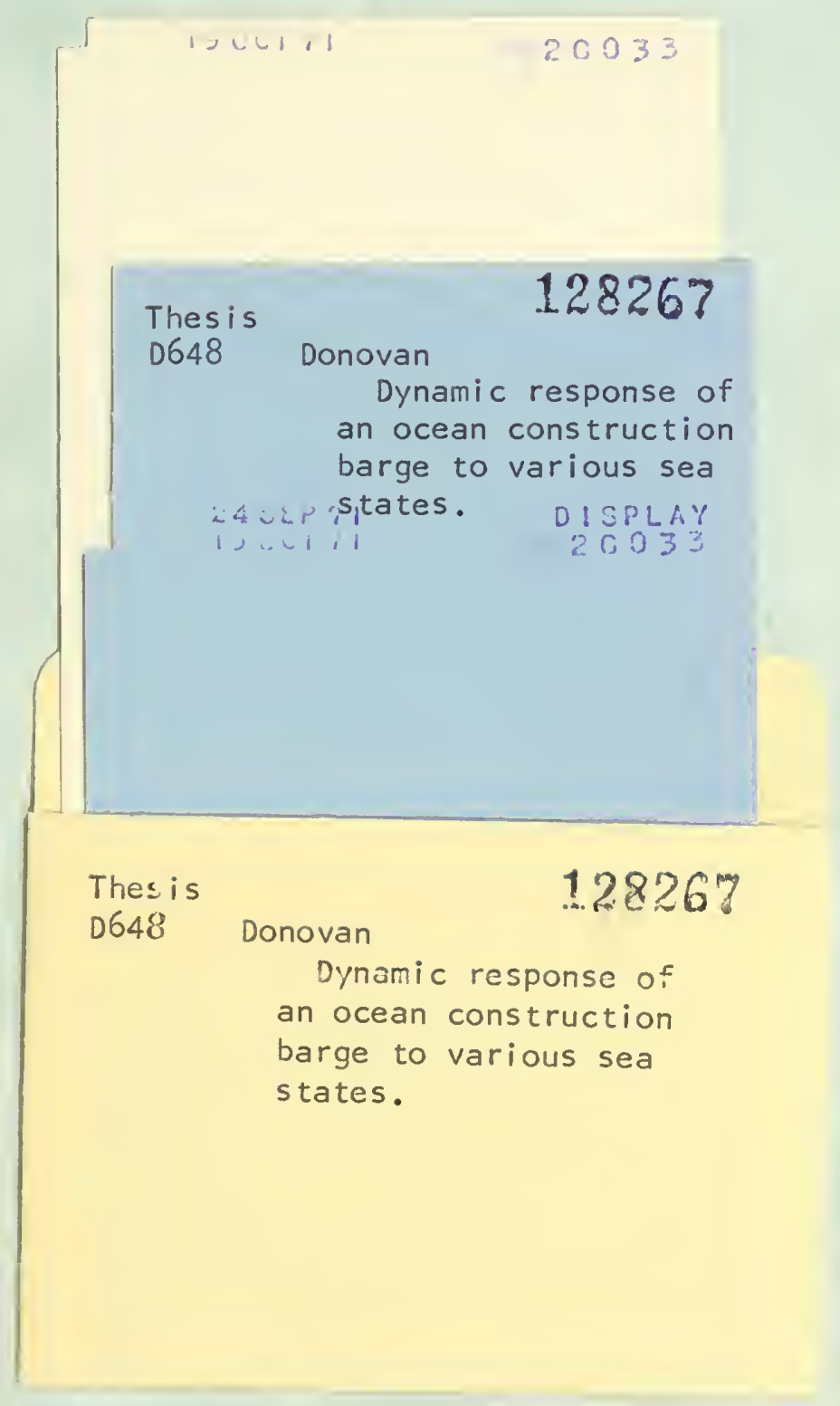


thesD648

Dynamic response of an ocean constructio

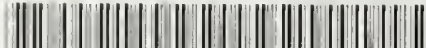

32768002005969 DUDLEY KNOX LIBRARY 